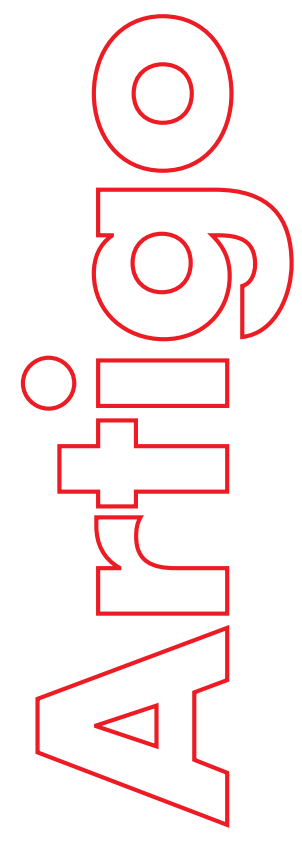

\title{
CIDADE E CAMPO: A REORGANIZACAOO TERRITORIAL DO MUNICÍPIO DE CRISTALINA-GO E O IMPACTO DO AGRONEGOCIO NO CERRADO
}

\section{Gustavo Silveira Tolentino Fernando Luiz Araújo Sobrinho}

p. $52-65$

Revista

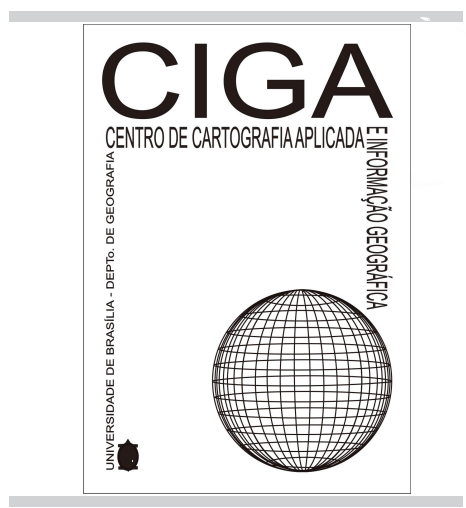

Revista Eletrônica:

Tempo - Técnica - Território,

V.10, N.1 (2019), 52:65

ISSN: $2177-4366$

DOI: https://

doi.org/10.26512/

ciga.v10i1.23853

Data de envio:

30/03/2019 Data de

aceite: 02/09/2019
Como citar este ar tigo:

Tolentino, G; Sobrinho, F. L. A; CIDADE E CAMPO: A REORGANIZAÇÃO TERRITORIAL DO MUNICÍPIO DE CRISTALINA-GO E O IMPACTO DO AGRONEGÓCIO NO CERRADO. Revista Eletrônica: Tempo - Técnica Território, v.10, n.1 (2019), p. 52:65 ISSN: 2177-4366. DOI: https:// doi.org/10.26512/ciga.v10i1.23853

\section{Disponível em:}

http://periodicos.unb.br/index.php/ciga/

Este obra está licenciado com uma Licença Creative Commons Atribuição-NãoComercial 4.0 Internacional. 


\title{
CIDADE E CAMPO: A REORGANIZAÇÃO TERRITORIAL DO MUNICÍPIO DE CRISTALINA-GO E O IMPACTO DO AGRONEGÓCIO NO CERRADO
}

\author{
Gustavo Silveira Tolentino \\ Graduando em Geografia \\ gustavosilveira.t@gmail.com \\ Fernando Luiz Araújo Sobrinho \\ Professor doutor do departamento de Geografia da Unidade de Brasília \\ flasobrinho@gmail.com
}

RESUMO: Diante ao avanço agrícola e de novos recursos tecnológicos na região do centro oeste, o município de Cristalina (GO) começa a apresentar formas e estruturas características de uma cidade do agronegócio. E consequência dessa expansão, cobiçou-se entender neste artigo, os impactos ambientais causados pelo agronegócio no Cerrado goiano, com ênfase no município de Cristalina-GO. Além desse aspecto, as relações sociais e econômicas foram relevantes para o desenvolvimento da pesquisa. Após esse processo, foi realizada uma análise da área de plantações agrícolas com as áreas de Cerrado preservado com intuito de compreender a relação entre o avanço agrícola com o crescimento urbano da região.

ABSTRACT: In face of the agricultural advance and the new technological resources in the Central West region, the municipality of Cristalina $(G O)$ begins to present forms and structures characteristic of an agribusiness city. And as a consequence from this expansion, this article intents to understand the environmental impacts caused by the agribusiness in the goiano Cerrado, focusing in the municipality of Cristalina-GO. Beyond this aspect, social and economic relations were relevant to the development of the research. After this process, an analysis of the agricultural plantation area with the preserverd Cerrado areas was made in order to comprehend the relation between the agricultural progress and the urban growth of the region.

Palavras chave: Cerrado; agronegócio; pivô central; Cristalina; cidade do agronegócio.

\section{INTRODUÇÃO}

Localizado no Brasil central, ao sudeste de Brasília, o município de Cristalina-GO tem todo o seu território como parte integrante do domínio morfoclimático do Cerrado em uma área de 6.162,089 $\mathrm{km}^{2}$ de extensão $\quad$ segundo o Instituto Brasileiro de Geografia e Estatística (IBGE). Além disso, os dados apresentam um município com estimativa populacional de 55.347 habitantes 
relacionados ao ano de 2017. Atualmente a região se destaca por ser um dois maiores pólos de concentração do agronegócio brasileiro e, conforme destacam Michelotto e Sobrinho (2017), há em Cristalina, uma intensa e moderna produção agrícola, configurando-se como a maior área irrigada da América Latina.

No passado o município foi reconhecido como a "capital dos cristais" devido à extração de cristais durante meados do século XIX até a metade do século XX. Durante essa época a economia se baseava na exploração de cristais, onde tinha como destino final a exportação para o continente europeu (CRISTALINA, 2017). Posteriormente, na década de 70, a expansão agrícola começa a moldar a paisagem do Cerrado presente em Cristalina. Essa mudança se intensificou com o incentivo do governo que acarretou na chegada de produtores rurais, em grande maioria, da região sul do Brasil.

Nessa época o Centro Oeste começa a sofrer influência da implantação de diversos recursos tecnológicos que tinham como objetivo melhorar as condições de produção de commodities voltadas para o mercado externo. Esse processo desencadeou a implantação de grandes lavouras na região e, comitantemente, a ocupação do agronegócio no território de Cristalina gerou expressivo crescimento urbano da cidade.

É possível dizer que o município do leste do Goiás se encaixa na classificação da cidade do agronegócio como apresentada por Denise Elias e Renato Pequeno (2007 p.25). Em termos teóricos apresentados por Elias, a expansão do agronegócio pode desencadear novas funções para a cidade, que passa a ser claramente funcional para o atendimento das demandas produtivas associadas à modernização da agricultura, como podemos ver a seguir:

“É possível identificar no Brasil agrícolas modernos vários municípios cujas urbanização se deve diretamente a consecução e expansão do agronegócio, formando-se cidades cujas função principal claramente associada às demandas produtivas dos setores de modernização da agricultura - sendo que nestas cidades se realiza a materialização das condições gerais de produção do capital do agronegócio" (ELIAS, PEQUENO, 2007 p.25).

Os efeitos do avanço da expansão agrícola desencadeou no Cerrado uma grande perda do domínio morfoclimático na região do estado do Goiás. Em decorrência dessas ações o município de Cristalina (GO) passa a apresentar características de uma cidade do agronegócio, como apresenta Elias e Pequeno (2007). 
Com isso, o artigo tem como objetivo analisar os impactos ambientais causados pelo agronegócio no Cerrado, com ênfase no município de Cristalina (GO). O artigo está organizado em duas partes e por fim as considerações finais. Primeiramente será apresentado à mudança do Cerrado por meio da expansão agrícola junto à conceituação de termos aplicados à ocasião. A segunda parte está organizada na análise de estrutura montada para atender o agronegócio na cidade de análise.

\section{METODOLOGIA}

A metodologia utilizada para a produção do trabalho foi dividida em três etapas. Inicialmente foi realizada uma pesquisa documental em busca sobre as características históricas e atuais do domínio morfoclimático do Cerrado na região de estudo. Nesse processo foi necessário o levantamento bibliográfico de pesquisas já realizadas e de conceitos que poderiam ser utilizados no desenvolvimento da pesquisa. $\mathrm{O}$ exemplo destas pesquisas foi encontrado trabalhos referentes ao uso do solo, vegetação, desmatamento, espaço urbano e rural da região de Cristalina.

A segunda etapa foi realizada por intermédio do levantamento de dados sobre as características que propiciaram a formação do agronegócio, do espaço rural e urbano do município. O intuito dessa etapa é fundamental para o entendimento da formação da cidade e se suas funções são voltadas para as necessidades do agronegócio e, consequentemente, quais impactos ambientais foram causados por meio desse processo.

Por último será realizada uma comparação dos dados obtidos com os conceitos abordados durante o desenvolvimento da pesquisa. Os dados serão especializados por meio da utilização de mapas produzidos por meio do software QGIS e serão utilizados no decorrer da pesquisa.

Os dados levantados serão obtidos pelo Instituto de Geografia e Estatística (IBGE), Companhia de Planejamento do Distrito Federal (CODEPLAN), Instituto Chico Mendes de Conservação da Biodiversidade (ICMBIO) e Superintendência do Desenvolvimento do Centro Oeste (SUDECO).

\section{RESULTADOS}

Segundo Bessa (2006), para falar da expansão agrícola do Cerrado goiano é necessário ressaltar que a região sempre teve "vocação rural", sendo possível identificar até os dias de hoje. Para a autora, a economia do estado goiano pode ser divida em duas fases: antes e depois da década de 1970 (2006, p.17). Antes da década de 1970, o estado de Goiás tinha sua economia voltada principalmente pela extração de minerais volvida para o mercado externo. Segundo Souza (2005) e Bessa (2006), Revista Eletrônica: Tempo - Técnica - Território, V.10, N.1 (2019), 52:65 ISSN: 2177-4366 
ocorriam, junto ao contexto histórico, à ocupação dos bandeirantes na região do centro oeste com objetivo da extração dos minerais da região.

A construção de Brasília em 1960 e o surgimento de rodovias que integravam a região do centro oeste brasileiro influenciaram na expansão agrícola no estado de Goiás, dando destaque ao município de Cristalina. O município esta localizado a $130 \mathrm{~km}$ de distância da capital federal e é constituída por diversas características de cidade voltada para as necessidades técnicas das grandes lavouras agrícolas.

O município goiano resume, em partes, o que Milton Santos e Maria Laura Silveira (2001) algam como modernização da agricultura no Brasil. Os autores entendem que as inovações técnicas e organizacionais na agricultura influenciam diretamente em um novo uso do tempo e de um novo uso da terra, como apresentado a seguir:

\footnotetext{
"Inovações técnicas e organizacionais na agricultura concorrem para criar um novo uso do tempo e um novo uso da terra. O aproveitamento e momentos vagos no calendário agrícola ou encurtamento dos ciclos vegetais, a velocidade da circulação de produtos e de informações, a disponibilidade de crédito e a preeminência dada à exportação constituem, certamente, dados que vão permitir reinventar a natureza, modificando solos, criando sementes e até buscando, embora pontualmente, impor leis ao clima." (SANTOS e SILVEIRA, 2001 p.118).
}

O "novo uso do tempo e um novo uso da terra" podem ser citados na nova paisagem do Cerrado goiano após o avanço da fronteira agrícola. A chegada de produtores rurais do sul do país na década de 70 no município e Cristalina influenciaram na transformação da paisagem natural do Cerrado. O que antes era lugar de extração de minério passa a se tornar um lugar de plantio de diferentes culturas que constituíram uma nova paisagem, passando de um Cerrado nativo para uma grande área antropizada (IBGE, 2018).

Cristalina localiza-se em uma região com temperaturas amenas com relevo plano, de solos propícios por meio de aditivos químicos, ao cultivo agrícola e, além disso, é beneficiado por mais de 240 nascentes e rios que dão suporte a instalação de 572 pivôs central (mapa 1), (EMBRAPA 2013). A instalação desses pivôs desencadeou uma transformação na paisagem do Cerrado por meio da realização de colheitas durante todas as épocas do ano, com isso, o município passou a ser gradativamente ocupado pela expansão agrícola, ocasionando assim, uma transformação da paisagem da flora e da fauna. Assim sendo, a região começa a ter mais parcelas de grandes plantações em seu território do que o Cerrado característico. 
A modernização no campo do município de Cristalina, sobretudo na década de 1990 e 2000, ocasionou profundas mudanças no ecossistema dos Cerrados que apresentam hoje, grandes áreas antropizadas como apresentada no mapa a seguir (mapa 2). O mapa apresenta as maiores parcelas de desmatamento no município de Cristalina durante dois períodos, sendo o primeiro entre 1970 até 2000 e o segundo até o ano de 2013. É possível notar nitidamente que a maior parcela de desmatamento ocorreu entre as décadas de 1970 - 2000 devido ao avanço da ocupação agrícola nas Chapadas do Sudeste Goiano. Além disso, como comentado anteriormente, é possível notar a quantidade de pivôs central em todo o território de Cristalina.

\section{MAPEAMENTO DOS PIVÔS CENTRAL NO MUNICÍPIO DE CRISTALINA DE GOIÁS}

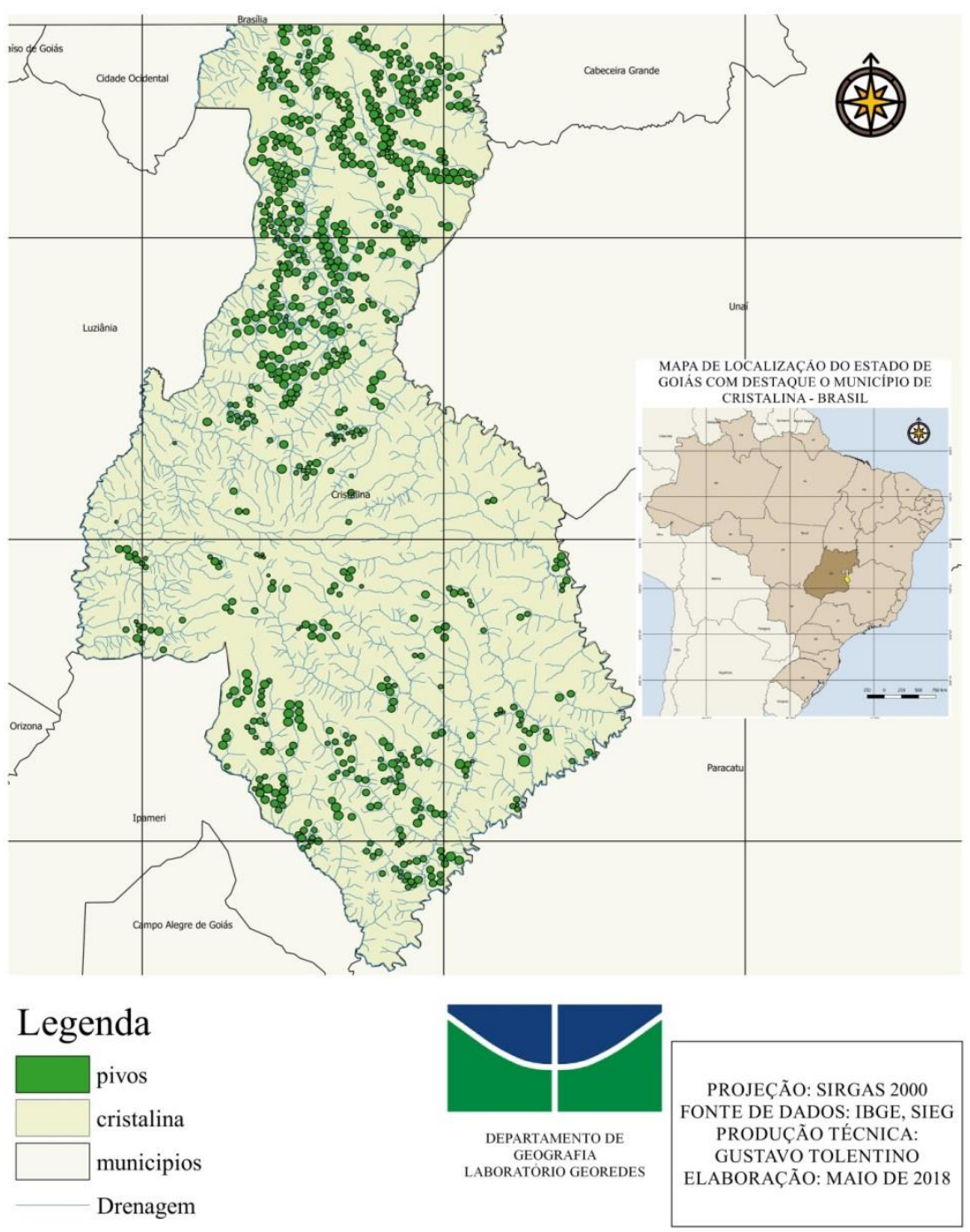


Mapa 1: Concentração de mais de 570 pivôs na região de Cristalina de Goiás. Fonte: IBGE, SIEG. Produção: Gustavo Tolentino

\section{DESMATAMENTO DO CERRADO NO MUNICÍPIO DE CRISTALINA DE GOIÁS}

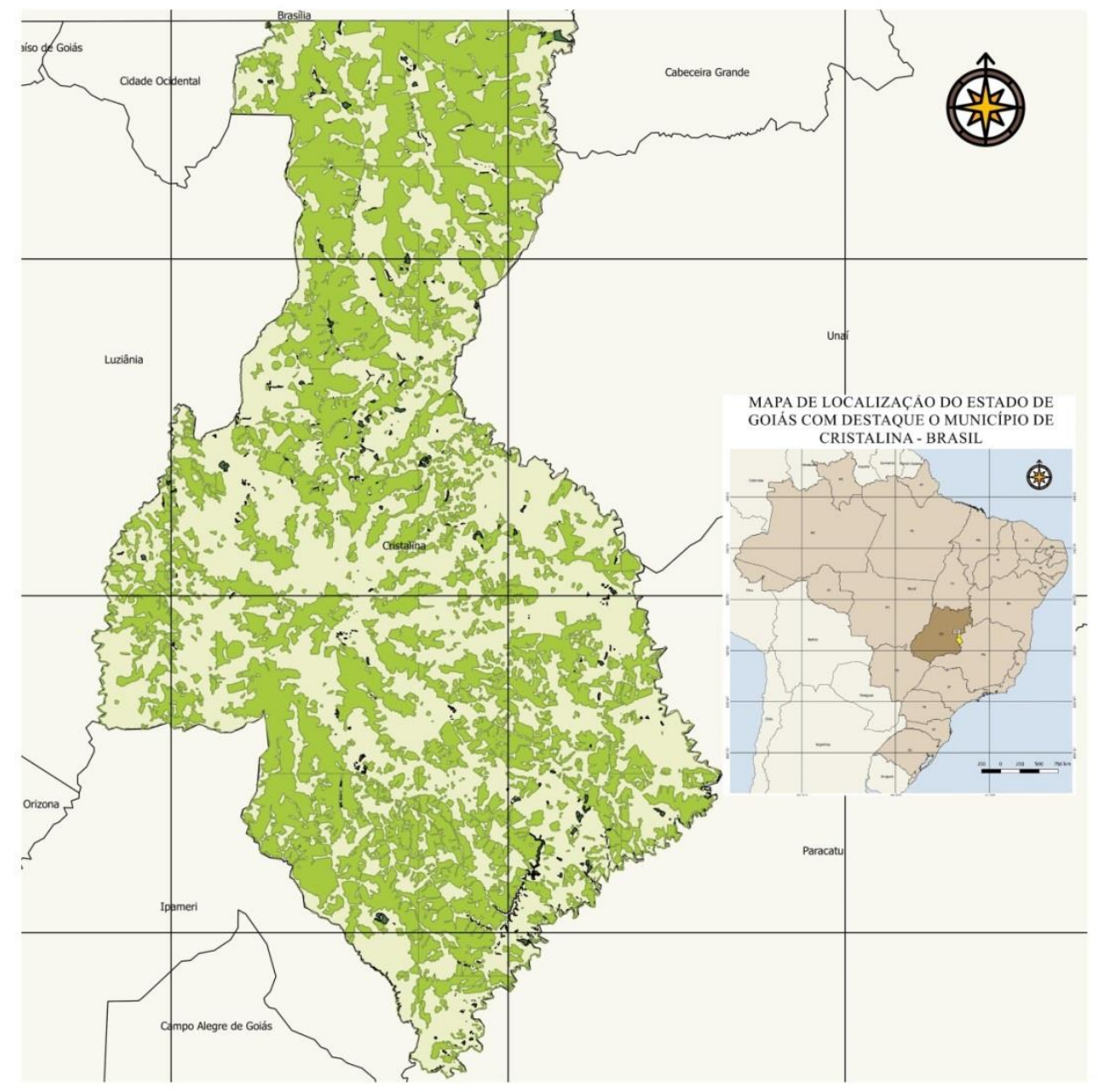

\section{Legenda}

Desmatamento durante $1970-2000$
Desmatamento após o ano de 2013
Delimitação de Cristalina
$\square$ Municípios vizinhos

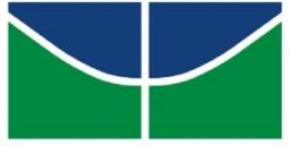

DEPARTAMENTO DE GEOGRAFIA
LABORATORIO GEOREDES
PROJEÇÃO: SIRGAS 2000 FONTE DE DADOS: IBGE, SIEG PRODUČÃO TÉCNICA: GUSTAVO TOLENTINO ELABORAÇÃO: MAIO DE 2018

Mapa 2: Desmatamento do cerrado no município de Cristalina de Goiás. Nota-se que grande parte do domínio morfoclimático do Cerrado foi devastado durante as décadas de 1970 e 2000.

O impacto na paisagem do campo e da cidade é nítido pela grande área desmatada, chegando a ter mais de 60\% da vegetação nativa retirada (MMA 2011), ocasionando assim, uma transformação da paisagem do domínio morfoclimático da região. Em relação ao desmatamento, grandes áreas agrícolas 
começam a fazer parte do território de Cristalina que ocasionam algumas transformações no espaço urbano e rural do município.

\section{RELAÇÃO DO CAMPO COM A CIDADE, UMA JUNÇÃO DOS ESPAÇOS.}

Além dos aspectos citados anteriormente, é possível notar que a ocupação agrícola no território de Cristalina passa a ser conectado por rodovias federais (BR 040 e BR 050) que desenvolvem um papel fundamental para o fluxo de cargas e produtos que atendem as demandas do agronegócio, e pelo desenvolvimento urbano por meio da modernização agrícola. Tais aspectos se encaixam nos conceitos de Denise Elias e Renato Pequeno acerca da expansão dos modelos agrícolas como apresentado a seguir:

\footnotetext{
“A expansão dos modernos sistemas de objetos (Santos, 1994, 1996), especialmente associados aos transportes, às comunicações, à eletrificação e ao saneamento, equipou o território nacional para a modernização agrícola e industrial, assim como para a intensificação das trocas comerciais, possibilitando a integração territorial do país, interligando áreas até então desconectadas." (ELIAS e PEQUENO, 2007 p. 25).
}

A partir do ano de 2010 o município passou a industrializar grande pare da sua produção, chamando assim, a atenção das indústrias Incrontril, Fugini, Bonduelle e Sorgatto Alimentos, que iniciaram o pólo de alimentos plantados na própria região (IBGE, 2018).

Segundo Corrêa (2007), Michelotto e Sobrinho (2017), hoje, a cidade de Cristalina pode ser considerada, de acordo com termos de Santos (1996), como uma cidade local e pequena que tendem a caminhar, por meios de suas projeções populacionais e de organização do espaço intraurbano, para a concepção de uma cidade média para os próximos 15 anos.

Com isso é possível observar estruturas e elementos novos em todo o território de Cristalina. É perceptível a presença dessas estruturas através de diversos silos, comércios de máquinas agrícolas, lojas de sementes, de produtos químicos de diversos usos e outros materiais e objetos utilizados para o atendimento e funcionamento das necessidades do campo.

Segundo o Cadastro Central de Empresas (CCE) obtidos pelo IBGE, cerca de 50 empresas voltadas para a agricultura, pecuária, produção floresta, pesca e aquicultura abriram em Cristalina no período de 1967 até 2016. Os dados mostram também que as maiorias das empresas se instalaram a partir do ano de 2000. A tabela 1 o número de empresas relacionadas a esses serviços. Os dados relacionados foram obtidos pelo IBGE. 
TABELA 1 - EMPRESAS E OUTRAS ORGANIZAÇÕES, POR ORGÃO DA CLASSIFICAÇÃO DAS ATIVIDADES (CNAEA 2.0), FAIXAS DE PESSOAL OCUPADO - TOTAL E ANO DA FUNDAÇÃO CRISTALINA DE GOIÁS.

\begin{tabular}{c|c|c|c|c}
\hline Ano de fundação & $\begin{array}{c}\text { A agricultura, pecuária, } \\
\text { produção florestal e pesca }\end{array}$ & $\begin{array}{c}\text { Indústrais } \\
\text { extrativas }\end{array}$ & $\begin{array}{c}\text { Indústrias de } \\
\text { transformação }\end{array}$ & Construção \\
\hline Até 1966 & - & - & - & - \\
\hline 1967 a 1970 & - & - & 1 & - \\
\hline 1971 a 1980 & - & - & - & - \\
\hline 1981 a 1990 & 5 & 1 & 1 & 1 \\
\hline 1991 a 1995 & 2 & - & 4 & 1 \\
\hline 1996 a 2000 & 3 & - & 1 & 3 \\
\hline 2001 a 2003 & 2 & - & 8 & - \\
\hline 2004 & 1 & - & - & - \\
\hline 2005 & - & - & - & - \\
\hline 2006 & 1 & 1 & - & - \\
\hline 2007 & 1 & - & 2 & 2 \\
\hline 2008 & 2 & - & 4 & 9 \\
\hline 2009 & 3 & 1 & 5 & 2 \\
\hline 2010 & 4 & 1 & 2 & 6 \\
\hline 2011 & 6 & 1 & 4 & 4 \\
\hline 2012 & 2 & - & 1 & 3 \\
\hline 2013 & 5 & - & 7 & \\
\hline 2014 & 7 & - & 3 & 6 \\
\hline 2016 & 2 & & & \\
\hline
\end{tabular}

FONTE: IBGE - CADASTO CE TRAL DE EMPRESS

O crescimento dessas empresas após da década de 1970 desencadeou várias demandas de serviços para a região. Em decorrência disso, o processo de migração para o município começou a se intensificar e ocasionou com a chegada de pessoas ao longo dos anos. Para a compreensão desse avanço, foi realizado um levantamento de dados censitários dos anos 2000, 2010 e a população estimada para o ano de 2017 (IBGE), como apresentado a seguir:

TABELA 2: POPULAÇÃO TOTAL DO MUNICÍPIO DE CRISTALINA, DO ESTADO DO GOIÁS E BRASIL

\begin{tabular}{|c|c|c|c|}
\hline \multirow[t]{2}{*}{ UNIDADES TERRITÓRIAIS } & \multicolumn{3}{|c|}{ POPULAÇÃO RESIDENTE POR ANO } \\
\hline & 2000 & 2010' & 2017 \\
\hline Cristalina - GO & 34.116 & 46.580 & 55.347 \\
\hline Goiás & 5.004 .197 & 6.003 .788 & 6.778 .772 \\
\hline Brasil & 169.872 .856 & 190.755 .799 & 207.660 .929 \\
\hline
\end{tabular}

FONTE: FONTE: IBGE - CENS DEMOGRÁFICO, 2000 - 2010, IBGE ARONAMA.

Em consequência do crescimento populacional, o espaço urbano acabou se expandido simultaneamente ao longo dos anos. A organização da mancha urbana se consolidou ao redor das rodovias federais, as BR - 040 e BR - 050 e apresenta crescimento notório em um período de vinte anos.

Revista Eletrônica: Tempo - Técnica - Território, V.10, N.1 (2019), 52:65 ISSN: 2177-4366 
Para a análise da expansão da mancha urbana foi realizada o levantamento de imagens de satélites obtidas pelo Google Earth em um intervalo de tempo de vinte e seis anos. Além disso, as imagens foram divididas em períodos de dez anos entre cada figura, com exceção do ano de 2016, que foi incluída para retratar o cenário mais atual disponível pelo Google Earth. A figura 1 e apresenta o crescimento da mancha urbano durante esse período.

A expansão urbana da região originou se junto ao avanço do agronegócio, apresentando assim, um adensamento da cidade próximo às rodovias para escoamento das produções agrícolas. Porém, o que mais se destaca nessas expansões é a integração à economia urbana e o campo, que segundo Elias e Pequeno (2007), é uma das características do agronegócio globalizado. Para os autores esse processo gera uma extensa gama de novas relações campo-cidade, como apresentado a seguir:

\footnotetext{
"Dentre as características do agronegócio globalizado está sua forte integração à economia urbana, gerando uma extensa gama de novas relações campo-cidade, diluindo, em parte, a clássica dicotomia entre estes dois espaços." (ELIAS e PEQUENO, 2007 P.26).
}

É possível notar que o território estudado apresenta uma nova estruturação que beneficia uma nova logística de atendimento a produção agrícola globalizada. Assim, Cristalina passa ter grande parte da sua produção voltada ao mercado globalizado, que acarreta em uma transformação de produção agrícola local para produção de grandes plantações de commodities. Para auxílio dessa análise, a tabela 3, apresenta dados obtidos pelo IBGE referentes à área plantada, área colhida e quantidade produzida em um intervalo a cada dez anos, com exceção do ano de 1974. 


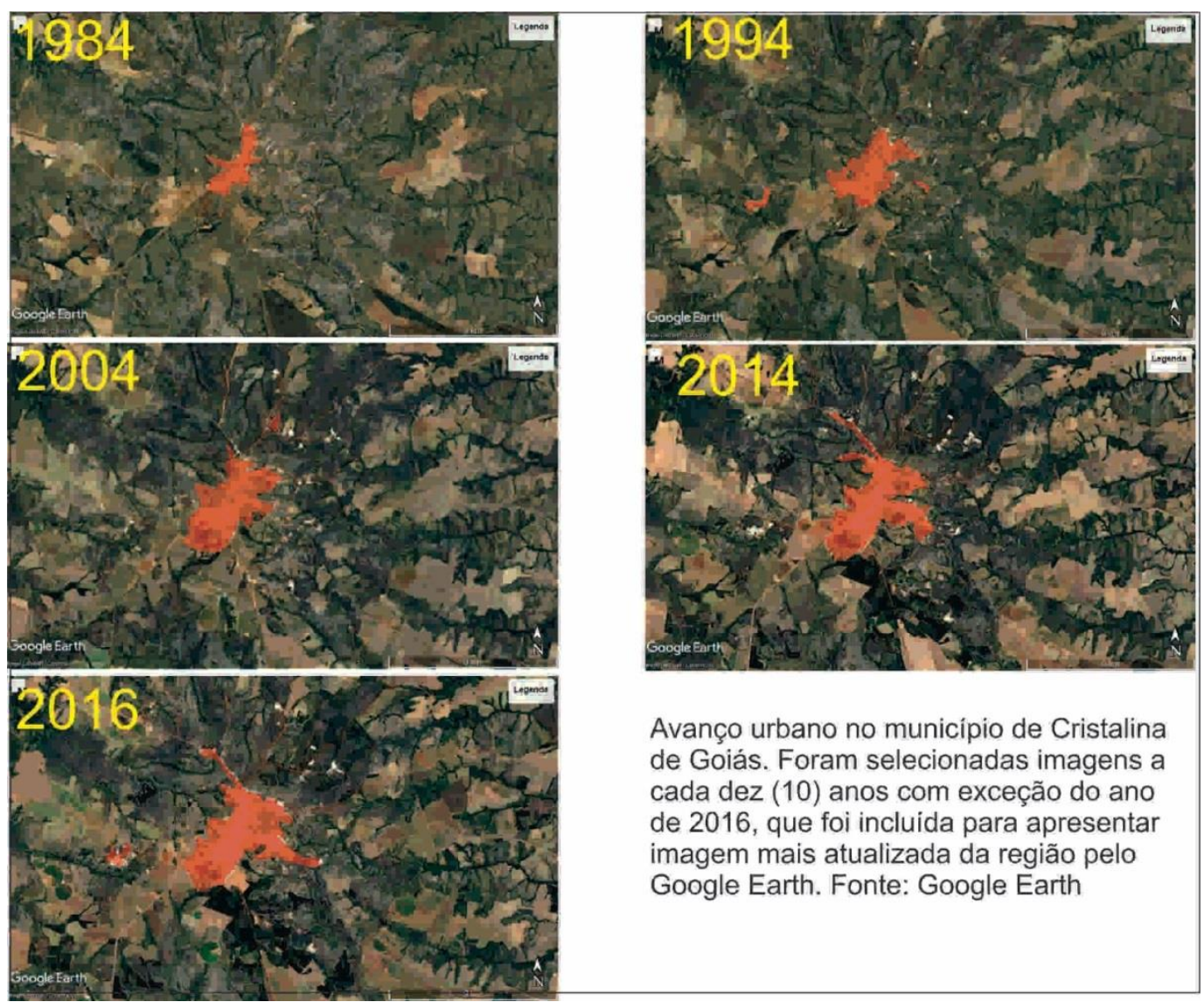

Figura 1 Avanço urbano do município de Cristalina de Goiás durante os anos de 1984 até 2016.

TABELA 3 - ÁREA PLANTADA, ÁREA COLHIDA, QUANTIDADE PRODUZIDA, RENDIMENTO MÉDIO DAS LAVOURAS TEMPORÁRIAS NO MUNICÍPIO DE CRISTALINA - GO

Variável - Área colhida (Hectares) Produo das lavouras temporárias - Total

\begin{tabular}{l|l|l|l|l|l|l}
\hline Ano & 1974 & 1980 & 1990 & 2000 & 2010 & 2016 \\
\hline Brasil & 35.514 .054 & 42.397 .183 & 43.497 .198 & 44.022 .212 & 58.332 .399 & 69.600 .219 \\
& & & & & & \\
\hline Cristalina (GO) & 2.470 & 11.684 & 59.796 & 123.675 & 310.690 & 368.110 \\
\hline
\end{tabular}

FONTE: IBGE - PRODUÇÃO AGRICOLA MUNICIPAL

Os dados colhidos estão concordantes com o desenvolvimento da pesquisa, sendo possível correlacionar à expansão agrícola com o crescimento urbano e a transformação da área rural, por meio do crescimento das áreas plantadas em hectares. Essas mudanças gera diversos impactos no Cerrado, como a mudança da paisagem, danos à fauna e a flora, descaracterização da região, porém, para a economia local, a expansão agrícola é apresentada de forma positiva.

Revista Eletrônica: Tempo - Técnica - Território, V.10, N.1 (2019), 52:65 ISSN: 2177-4366 
É possível notar que no ano de 1974, começo da expansão agrícola no Centro Oeste, o município de Cristalina tinha 2.470 hectares plantados. Já em 1990, década da intensa ocupação agrícola da região, passa a ter quase 60 mil hectares plantados. Nas décadas seguintes o crescimento é gradativo, 123.675 hectares em 2000 para 369.110 hectares plantados em 2016. A tabela 4 apresenta o valor da produção das lavouras temporárias da área de estudo.

\section{TABELA 4 - VALOR DA PRODUÇÃO DAS LAVOURAS TEMPORÁRIAS}

\begin{tabular}{|c|c|c|c|c|c|c|}
\hline \multicolumn{7}{|c|}{ Variável - Valor da produção - Produtos das lavouras temporárias no município de Cristalina de GO } \\
\hline Ano & $\begin{array}{l}1974 \quad \text { (Mil } \\
\text { Cruzeiros) }\end{array}$ & $\begin{array}{l}1980 \quad \text { (Mil } \\
\text { Cruzeiros) }\end{array}$ & $\begin{array}{l}1990 \quad \text { (Mil } \\
\text { Cruzeiros) }\end{array}$ & $\begin{array}{l}2000 \text { (Mil } \\
\text { Reais) }\end{array}$ & $\begin{array}{ll}2010 & \text { (Mil } \\
\text { Reais) } & \\
\end{array}$ & $\begin{array}{ll}2016 & \text { (Mil } \\
\text { Reais) } & \end{array}$ \\
\hline Brasil & 53.373 .550 & 739.130 .343 & 1.288 .646 .590 & 34.578 .507 & 121.380 .907 & 261.531 .256 \\
\hline Cristalina (GO) & 2.832 & 176.830 & 1.693 .030 & 119.702 & 1.021 .836 & 1.847 .971 \\
\hline
\end{tabular}

FONTE: IBGE - PRODUÇÃO MUNICIPAL

O valor da produção tá correlacionada ao crescimento da área plantada. O valor é importante para a o desenvolvimento econômico da região e sua influência se caracteriza na paisagem urbana e rural, tornando assim, uma território responsável para suprir as necessidades, como mão de obra ou recursos financeiros, insumos, máquinas, assistências técnicas e outros meios que atendem a demanda do agronegócio. Para Elias e Pequen (2007), o geográfo Milton Santos alega que esse desenvolvimento torna a aplicabilidade do termo da cidade campo, como podermos ver a seguir:

“As cidades próximas às áreas de realização do agronegócio tornam-se responsáveis pelo suprimento de suas principais demandas, seja de mão de obra, recursos financeiros, aportes jurídicos, de insumos, de máquinas, de assistência técnica etc, aumentado à economia urbana e promovendo redefinições regionais - denotado o que Milton Santos chamou de cidade campo" (ELIAS e PEQUENO, 2007 P.26).

O crescimento do município originou o surgimento de novas construções no meio rural, desenvolvendo assim, o crescimento da cidade junto ao campo, desencadeando uma grande área antropizada e de descaracterização da vegetação nativa para o surgimento de áreas urbanas e rurais conectadas, ou rururbana, como apresentado por Milton Santos. Esse crescimento das grandes lavouras de commodities passa a entender as novas tecnificação da globalização e, consequentemente, acarreta um elevado desmatamento do Cerrado. 


\section{CONSIDERAÇÕES FINAIS}

Através dessa pesquisa foi possível perceber a vasta transformação que a ocupação agrícola causou para o município de Cristalina. Ao longo dos anos a cidade passou a ser alicerce do agronegócio e, para manter o título da maior região de pivôs centrais da américa latina, foi necessário por parte do município, realizar diversas mudanças de acordo com as demandas e necessidades da produção agrícola globalizada.

As consequências dessas demandas ocasionaram diversas mudanças como uma nova característica econômica e social. Esse processo é perceptível antes da década de 1970, onde a economia era voltada para extração de cristais e, após esse período, passa a ser sustentada em maioria pelo agronegócio. Essa mudança da economia reflete na expansão da agricultura que, contrapartida, apresenta um avanço de grandes parcelas do território compostas por lavouras e equipamentos de suportes agrícolas e do campo.

As causas e influências da expansão agrícola para o município tem gerado grande impacto ambiental. A delimitação do Cerrado apresentou grande perda e, consequentemente, a diminuição da fauna e da flora. Vale ressaltar que a transformação o Cerrado para as lavouras se deu de forma gradativa e intensa no período das décadas de 1970 e 1980, e até, essa transformação se deu seu uma análise técnica por parte do governo. Além disso, a prefeitura municipal destaca com o orgulho a quantidade de pivôs da região, porém, não apresenta uma proposta de análise de impacto ambiental.

Simultaneamente, a área urbana em apresentando elevado crescimento a partir da década de 1980 e maior intensificação no final da década de 1990. Este processo se deu por intermédio do êxodo rural proveniente da tonificação do meio de produção do campo e pelas necessidades que as pessoas estavam passando na cidade, como as lojas agrícolas, bancos, mercados e outros meios que dão suporte aos exercícios diários de uma cidade. Além disso, a mancha urbana se expandiu ao redor das BR-040 e BR-050, estruturando a partir delas, uma rota de fácil acesso a outras regiões de país como Brasília, Unaí e Belo Horizonte.

Por outro lado, o agronegócio tem desempenhado o papel de promover a produção agrícola do município, recebendo assim, destaque nacionalmente pela quantidade produzida e pelo grande número de pivôs e equipamentos de irrigação. Este processo acarretou a alavancamento econômico de Cristalina, 
Porém, este o crescimento econômico de Cristalina não significou uma melhora no desenvolvimento social da região, visto que grande dentro da expansão urbana é possível encontrar pessoas que vieram do campo por falta de trabalho por intermédio das novas técnicas adotadas no campo. Além disto, o município não suporta, em algumas áreas do território, condições básicas de vida para a população residente, apresentando assim, um crescimento econômico, mas não necessariamente o desenvolvimento social.

Por fim, ao promover uma maior ocupação territorial no território de Cristalina, o agronegócio gerou uma transformação da paisagem natural da região, passando do cerrado característico para grandes lavouras da produção de commodities e outros aportes técnicos que atendem suas necessidades. Com isso, a expansão agrícola desenvolveu um acelerado crescimento urbano da região como forma de estruturação para a produção agrícola.

\section{REFERÊNCIAS BIBLIOGRÁFICAS}

CARNEIRO, P. J. R. C. ET AL Evolução do uso da água na bacia do rio preto no distrito federal Espaço \& Geografia, Vol.10, No 2 (2007), 325:353

CORREA, R. L. Construindo o conceito de cidade média. In: Cidades Médias. Espaços em Transição. Org. M. Encarnação Beltrão Sposito. São Paulo: Expressão Popular, 2007. p. 23-33.

CRISTALINA. Prefeitura de Cristalina. Disponível em: https://cristalina.go.gov.br/

ELIAS, D. PEQUENO R. : Desigualdades socioespaciais nas cidades do agronegócio. Estudos urbanos e regionais. V.9, n.1 maio 2007.

EMBRAPA: Mapeamento das áreas irrigadas por pivôs centrais no Estado de Goiás e no DF. Brasília - DF

2013. Diponível em: https://portal-h.sede.embrapa.br/busca-de-publicacoes/-

/publicacao/974474/mapeamento-das-areas-irrigadas-por-pivos-centrais-no-estado-de-goias-e-no-distrito-

federal-brasil

GDF - Governo do Distrito Federal. (2013). Codeplan. Pesquisa Distrital por Amostra de Domicílios: PDAD 2013. Brasília, DF.

GONDIM, J. Principais conflitos por Usos Múltiplos no Brasil. Agência Nacional de Águas.

Disponível em:

http://www.abrh.org.br/xviiisbrh/apresentacoes/mr5joaquimgondim.pdf

http://www.cristalina.go.gov.br/sobre-o-municipio/economia/

https://portal-h.sede.embrapa.br/busca-de-publicacoes/-/publicacao/974474/mapeamento-das-areas-

irrigadas-por-pivos-centrais-no-estado-de-goias-e-no-distrito-federal-brasil

IBGE - Instituto Brasileiro de Geografia e Estatística. Censos Demográficos 2000 e 2010. Disponível em: < http://www.ibge.gov.br >. Acesso em: jun. 2016.

LEÃO, M. (Org.) O Direito Humano à Alimentação Adequada e o Sistema Nacional de Segurança Alimentar e Nutricional. Brasília: ABRANDH, 2013. 263 p.

MICHELOTTO, Letícia Del Grossi; SOBRINHO, Fernando Luiz Araújo. A pequena cidade no esteio do agronegócio: transformações socioespaciais no município de Cristalina GO. Disponível em: http://periodicos.uem.br/ojs/index.php/Geoinga/article/view/37853/19861 
MMA: Monitoramento do desmatamento nos biomas brasileiros por satélite. Acordo de cooperação técnica MMA/IBAMA. Brasília - DF agosto de 2011. Diponível em: http://www.mma.gov.br/estruturas/sbf chm rbbio/ arquivos/relatoriofinal cerrado 2010 final 72 1.pdf

SANTOS, Milton. A natureza do espaço: técnica e tempo, razão e emoção. 4. ed. São Paulo: Hucitec, 1996. SECRETARIA DE INFRAESTRUTURA E OBRAS - Plano de Gerenciamento Integrado de Recursos Hídricos do Distrito Federal Caderno Distrital de Recursos Hídricos. Brasília - DF, abril 2005.

SELBORNE, L. A ética do uso da água doce: um levantamento. 2001. UNESCO. Brasília.

SUDECO. Desenvolvimento do Centro-Oeste. Disponível em: http://www.sudeco.gov.br/ 